\title{
Comunicabilidade metafórica:
}

\author{
do sensível à designação ${ }^{1}$
}

Dina Maria MARTINS FERREIRA ${ }^{2}$

\begin{abstract}
Reciprocamente somos metafísicos sem o saber na proporção da usura das nossas palavras.
\end{abstract}

(Derrida, 1999, p. 252)

\section{Resumo}

O objetivo desse estudo é tentar demonstrar que o sentido primitivo pode ser entendido como pulsão metafórica da linguagem, que emerge no processo designativo. Segundo Derrida, o 'sopro' é linguagem não articulada, aquela que manifesta o sensível do ser humano, que, buscando realizar-se na linguagem articulada, opera o deslocamento de sentido. Esse percurso do sensível pode ser retratado pelo movimento respiratório: na inspiração o sopro se faz sentir, e na expiração emerge a fala cuja força designativa expressa o pertencimento identitário.

Palavras-chave: metáfora; grito primitivo; designação; força identitária.

\begin{abstract}
The objective of this paper is to attempt to demonstrate that the primitive sense can be understood as language metaphorical pulsation, which emerges in the designating process. According to Derrida, the 'blow' is inarticulate language, one that manifests the sensitive aspect in the human being, who, searching for fulfillment in articulate language, operates a glide in meaning. This route of the sensitive can be portrayed by the respiratory movement: in inhalation, the 'blow' is perceived, while in exhalation there is the emergence of speech, whose designating strength expresses the identity belonging.
\end{abstract}

Keywords: metaphor; primitive blow; designation; identity force.

\footnotetext{
${ }^{1}$ Trabalho apresentado à quarta edição da Revista Ação Midiática - Estudos em Comunicação, Sociedade e Cultura, publicação ligada ao Programa de Pós-Graduação em Comunicação e Sociedade, da Universidade Federal do Paraná.

${ }^{2}$ Doutora pela Universidade Federal do Rio de Janeiro/UFRJ (1995); $1^{\circ}$ Pós-doutorado pela Universidade Estadual de Campinas/UNICAMP (2003); $2^{\circ}$ pós-doutorado pela Université Paris V, Sorbonne e Unicamp (2010). Professora Visitante do Programa de Pós-Graduação em Linguística Aplicada da Universidade Estadual do Ceará/UECE. Contato: dinaferreira@terra.com.br
} 


\section{Considerações}

Partindo de uma imagem, um fotojornalismo, vimo-nos atenta, senão abalada, com a relação que se estabelecia entre o icônico e o verbal. Indagávamos se a metáfora linguística ali presente não teria uma natureza metafórica anterior ao deslocamento do sentido e à expressão linguística que ali se manifestava.

O fotojornalismo mostrava uma criança em cima de uma carroça, puxada por um boi. A criança, vestida com roupas simples, segurava a guia condutora do boi, e acima desse triângulo figurativo - criança, carroça e boi - havia um letreiro - "Roliúde Nordestina”. Imediatamente o imaginário se pergunta: o que Hollywood, local de glamour, fama e dinheiro, estava fazendo naquele território árido, chamado de nordestino, e retratado por ícones de um tempo de civilização mais atrasado aos olhos do senso comum. Afinal boi e carroça não compartilham o glamour do mundo desenvolvido! Que força designativa ali se processava?

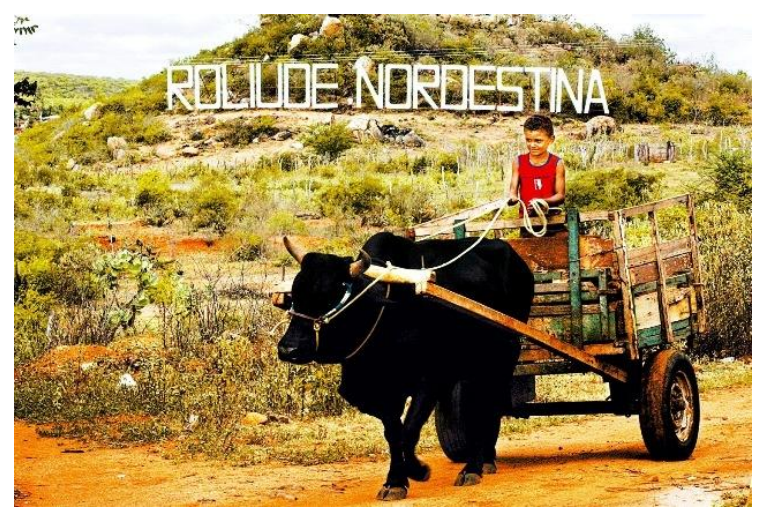

Figura $\mathrm{I}^{3}$

Mesmo tomando conhecimento descritivo do porquê da imagem na reportagem, o sensível do impacto permanecia. Tratava-se de uma reportagem sobre cinema. Era a apresentação de um set cinematográfico brasileiro, localizado na cidade de Cabaceiras, no Cariri do estado da Paraíba, a $189 \mathrm{~km}$ da capital do estado, com 5 mil habitantes. Ali já haviam sido rodados mais de 20 filmes brasileiros. Alguns fragmentos da narrativa:

\footnotetext{
3 Jornal Folha de São Paulo, São Paulo, 27 de maio de 2007, primeira página; imagem: Lalo de Almeida/Folha Imagem. Esse estudo é parte de uma pesquisa, da qual derivaram-se alguns outros artigos, apresentados em congressos no Brasil e no exterior.
} 
O idealizador do projeto 'Roliúde Nordestina', o escritor e pesquisador Wills Leal, 70, aponta, a partir de uma comparação com Hollywood, razões que levam os diretores a escolher Cabaceiras. (...) 'Os cineastas norte-americanos notaram que em Nova York chovia muito e havia muita neve. Perceberam que não havia luminosidade e que os prédios da cidade limitavam as opções de cenário' (...) 'O terceiro ponto que levou à procura de novos lugares foi a formação de sindicatos de atores, que passaram a exigir salários mais altos para os profissionais' (...) Para Leal, o Estado americano tem muitas semelhanças com o município paraibano. 'A Califórnia e Cabaceiras têm cenários desérticos, luminosidade, variedade de sets e mão de obra barata'. (...) 'Há diretores que criticam o uso da expressão 'roliúde', por considerar a comparação inadequada à realidade do local. Hollywood não é só um cenário. Há estúdios, dinheiro circulando. Cabaceiras não é isso, é um set de locação', diz Ana Bárbara Ramos (...) Apesar das analogias, Leal diz que a palavra 'roliúde' é apenas marketing - que faz questão de grafar "márquete"

Mesmo após a leitura da narrativa da reportagem em relação à manchete, o primeiro impacto não se desfaz. O determinante "nordestino" de uma "Hollywood" distorcida - "roliúde" -, já tinha tocado a pele. A força designativa da metáfora havia penetrado em minha pele.

E Derrida nos chama.

\section{A metáfora original}

Nosso percurso reflexivo inicia-se pela ideia do que seja metáfora original (Derrida, 1999), ou seja, a linguagem é, por sua própria natureza, metafórica, e não um sistema regulatório em que apenas o cognitivo age na construção de metáforas.

Apesar de o texto de Derrida, Mitologia Branca (1999) se ater ao estudo da metáfora em relação ao discurso filosófico, pergunto-me, como diz a epígrafe, se não continuamos, mesmo negando e brigando contra a metafísica, circulando em seu universo. Lutar contra a metafísica não seria uma forma de esconder a physis da meta-physis? $\mathrm{O}$ meta estaria buscando o inteligível e anulando o valor do sensível da carne, a physis?

Ao abordar o termo physis, não o estamos injetando na dicotomia platônica physisnomos e thesis (Platão, Crátilo, 1994), mas tomando por base o sentido aristotélico (Aristóteles, Physica VIII, 1969), de que as coisas 'animadas', vivas, têm dentro de si tanto o princípio do movimento quanto a pulsão do movimento. É por essa base aristotélica que ousamos formular que a physis, em nossa proposta, seria o movimento e o sentir do corpo;

${ }^{4}$ Cíntia Acayaba, Agência Folha, em $\quad$ Cabaceiras (PB). $\quad$ Fonte: http://www1.folha.uol.com.br/fsp/ilustrad/fq2705200715.htm, último acesso junho de 2008. 
não um corpo a que se confere uma matéria permanente, mas sim uma substância que articula o movimento do sensível, em sua multiplicidade, transitoriedade e mutabilidade. É a fisicalidade sentindo o sensível. E pensando nesse corpo, não teria ele a usura das palavras para se manifestar - palavras que dessem conta de designar o sensível que nos habita? Não seria a metáfora a expressão desse sensível?

Derrida (1999) discorre sobre a "usura" por palavras, como uma usura decorrente do excesso de uso de sentidos e palavras, cuja "gastura" revela outra usura, a busca de novos sentidos. Para explicar a usura das palavras, o autor faz uma analogia da linguagem com uma moeda, de modo a mostrar o sensível e o inteligível. Utiliza-se das reentrâncias da moeda, o exergo (local onde se coloca a data) e a efígie (a figura), como a moeda primeira, a que não foi ainda usada e manipulada. A moeda, no seu momento primitivo, mostra-se pelo sensível do tato, percebido por suas reentrâncias, mas, de tanto ser usada, essas reentrâncias se gastam, resultando em lisura. A lisura da moeda apagaria o seu lado primitivo, o exergo e a efígie, mas, de alguma forma, manteria o sensível pela representação que ali se estabelece. A moeda é a linguagem. Por essa argumentação, podemos afirmar que as noções abstratas, apesar da gastura do uso, ainda podem mostrar o sensível, nem que seja por sua representação em linguagem (Derrida, 1999).

O uso em demasia da palavra e seu consequente desgaste não altera a pulsão do sensível. A usura configura justamente o impulso de pôr para fora, em linguagem, o sensível que a gastura parece obstruir: a metáfora "longe de perder a entrada, faria frutificar a riqueza primitiva" (Derrida, 1991, p. 250). O sentido, querendo nós ou não, não perde sua história metafórica primeira. A argumentação, segundo esse mesmo autor (ibidem), é profícua, já que postula o grito primeiro do homem. Um bom exemplo é o gozo - um instante do sensível pleno em si mesmo; ou seja, se o gozo é o sensível, é um ato metafórico que pode se expressar linguisticamente. E perguntamo-nos: se o gozo pode ser considerado um grito primitivo, porque também qualquer outro grito do sentir da e na contemporaneidade não seria também um grito primeiro para quem grita? Mesmo que já estejamos em um momento civilizatório em que a linguagem se apresente em gastura, o sensível do homem continua 'desde sempre'. O vetor metafórico para o qual chamamos a atenção não se acaba pela gastura das palavras, ele 'apenas' se expressa pela representação que o exergo e a efígie podem oferecer - gastos mas existentes. O ef-facement, apagar a face, não elimina o grito do corpo. E como postula Derrida (1999, p. 252), "dever-se-ia sempre poder reativar a inscrição primitiva e restaurar o palimpsesto". E é nesse reativar 
do sentido que se processa a metáfora, sempre primitiva, mesmo que gasta pelo tempo de uso e como tal, muitas vezes, não a reconheçamos.

\section{Sensível e representação}

Estamos nos dirigindo sempre ao sensível como um grito primitivo não articulado; mas ao mesmo tempo podemos nos perguntar como esse sensível convive com a ideia de representacionalismo, já que aventei anteriormente que o sensível se manifesta mesmo que na representação linguajeira. Primeiro, esclarecemos que quando nos referimos ao sensível do corpo, seja este entendido como sujeito em linguagem articulada ou não-articulada, esse sensível não se estabelece, necessariamente, no essencialismo de uma metafísica. Como também já anunciamos anteriormente, estamos em physis, no corpo substanciado que sente, e não essencializado, como se ele se constituísse de um onto estável a priori.

A linguagem caminha na gastura de seu uso e por que não na gastura do corposensível? A natureza representacional da linguagem não impede que sua articulação emita e produza o que sentimos. Diria até que esse sensível representado e articulado tem de fazer muito mais esforço para ser ouvido, devido à impossibilidade de se alcançar o numenal $^{5}$, ampliando assim nossa "usura" de sentidos. Rajagopalan (2003, p. 31) exprime com pertinência como tal busca eclode no corpo-sensível:

\footnotetext{
A tese do representacionalismo é, ao mesmo tempo, uma lamentação e uma expressão de desejo. Ela é um gesto de lamentação porque afirma a incapacidade dos seres humanos de apreenderem o mundo numenal tal e qual (...). Por outro lado, ela também é uma expressão de um desejo, pois elege como condição ideal (...) a total transparência (itálicos acrescidos).
}

Se a busca de representação é lamento de não alcançar a presença de uma essência e desejo numenal nunca alcançado, como garimpar o sensível de nossas emoções na representação de linguagem? Por essa linha de pensamento, não queremos propor nem o esvaziamento nem o niilismo do sensível no representacionalismo, e sim demonstrar que as construções de e em linguagem podem e conseguem construir e atingir o nosso corpo-sensível. De outra maneira, com outro vocabulário, Derrida (1999) apoia esse lamento pelo que chama de "metafísica da presença", já que nenhum sentido é estável, está sempre em descentramento, apenas propiciando a ilusão de tê-lo alcançado - ilusão que

\footnotetext{
${ }^{5}$ Termo kantiano que indica "a coisa em si".
} 
não nos impede de sentir. Por essa situação de ilusão e de busca 'infindável', é que formulamos que o desejo de apresentação é o lamento das representações. Ou seja, a busca de representação configura o desejo da total transparência, que, impossibilitada de ser alcançada, torna-se a lamentação de um desejo não realizado. Lamentar e desejar não poderiam ser atributos constitutivos do que estou chamando de sensível?

Proponho uma ampliação desse sentir - lamento e desejo - pela analogia do conceito de representação com a de eidolon ${ }^{6}$, com o propósito de justamente ratificar que o sensível não nos abandona mesmo na possível 'aridez' da representação. Se tentarmos traduzir o sentido de eidolon diria que seria a 'presença de uma ausência', a saudade de uma presença que sentimos dentro de nós, que nunca tocamos. Eidolon seria o 'resíduo' e ou reflexo opaco de uma presença, e como tal nunca a coisa em si. Segundo Junito de Souza Brandão (1991, p. 22), eidolon como eidos "pressupõem o indo-europeu weid que exprime a ideia de 'ver' e de 'saber' (...), sendo eidolon uma réplica do morto, ele é uma imagem que se vê e, por conservar um resíduo latente de consciência, é algo que se sabe" (citado em Baitello Junior, serial) (itálicos acrescidos). Sabemos ou intuímos que há uma presença, mas só nos resta ter acesso à sombra dessa presença. Não poderíamos então predicar representação como um estado de eidolon? Estaríamos, talvez, hiperbolizando o postulado de Rajagopalan: um lamento de um desejo não realizado, que se "sabe" e se "vê" - o grito não-articulado -, exprimido pela representação de linguagem - o grito articulado. Se linguagem é representação das 'coisas' designadas, e sendo também a própria construção das coisas que percebemos (sentimos e vemos), os sujeitos, situados em seus tempos e espaços, utilizariam a natureza representacional da linguagem na emergência de seus sensíveis.

Voltemos, então, ao universo metafórico do grito primitivo, esteja ele representado em articulação ou não.

\section{Do deslocamento metafórico}

Se aceitarmos que a linguagem é ecológica (Martins Ferreira, 2006) ${ }^{7}$, pode-se entender a linguagem como a agricultura da terra, que, para brotar em sentidos e palavras,

\footnotetext{
${ }^{6}$ Eidolon, termo grego, que indica sombra, a sombra daqueles que já morreram e que ainda se movimento nas brumas.

${ }_{7}$ Termo utilizado pelo Prof. Dr. Kanavillil, Rajagopalan, no Curso de Pragmática, Pós-Graduação, IEL, Unicamp, segundo semestre de 2001 e citado na referida obra.
} 
é revolvida pelo arado que roda pela estrada do tempo cronológico. $\mathrm{O}$ arado caminha em movimento bustrofédico ${ }^{8}$, de tal forma que se mexe sem interrupção, o que permite que a terra 'antiga' - o sentido primitivo -, sempre possa emergir ao encontro da nova terra. Ou seja, a terra-linguagem recente, alimentada e nutrida pelo movimento do arado, emerge em sentidos novos misturando-se à gastura da terra antiga:

Trata-se da escritura por sulcos. O sulco é a linha, tal como a traça o lavrador: a rota - via rupta - cortada pela relha do arado. O sulco da agricultura, também o recordamos, abre a natureza à cultura. E sabe-se também que a escritura nasce com a agricultura, que não se dá sem a sedentarização (Derrida, 1999, p. 351).

Sob a ótica bustrofédica da linguagem, verifica-se que a continuidade de movimento permite reafirmar que a linguagem é ecológica, isto é, o processo de contínuo reaproveitamento não elimina sentidos primitivos, até porque o significado de reaproveitar já determina que algo existiu, e que portanto existe porque volta a aparecer. Se o processo de cultivo é contínuo, a cada plantio linguajeiro resíduos remanescentes de uma antiga plantação revolvem-se para se agregar à próxima; a terra-linguagem, na qual os sentidos e as palavras são plantados, não consegue eliminar e substituir os rastros de antigas plantações. O movimento bustrofédico, realizado pelo arado do boi, deixa sulcos e marcas, sulcos profundos ou não, cujas marcas e sentidos primitivos podem ser redescobertos.

O percurso da linguagem recebe os adubos de forma e conteúdo a cada espaçotempo percorrido, sem abrir mão do sensível, que nos parece cada vez mais denso se levarmos em conta a perspectiva evolucionista. Não um evolucionismo do logos, de homo erectus a homo sapiens, por exemplo, mas um alargamento do sensível, talvez hoje mais à flor da pele diante das múltiplas e complexas redes civilizatórias da contemporaneidade. Enfim, seja em que universo estejamos, do intelectivo à prática cotidiana, até "as noções abstratas escondem sempre uma figura sensível" (Derrida, 1999, p. 250).

8 Bustrofédon, a escritura de volta de boi (DerridA, 1999, pp. 351-352); palavra de origem grega que significa ao pé da letra volta do boi, bous está para boi e strophe para virada; "virando de uma linha para a outra, como fazem os bois ao passar de um sulco para outro, isto e, escrevendo alternadamente da esquerda para a direta e, depois, da direita para a esquerda, maneira de escrever usada em antigas inscrições gregas" (Machado, 1995, p. 477) . 


\title{
4. Da comunicabilidade metafórica
}

Ratificando que no universo conceitual ainda se chega ao sensível, utilizamo-nos de argumentos de Walter Benjamin (2001) sobre o processo designativo e a relação entre sujeito e objeto. $\mathrm{O}$ autor postula que a linguagem do homem tem a capacidade de dar nomes, ou seja, os homens falam objetos, no entanto os objetos também falam ao homem. Não seria, então, os impulsos sensíveis que fazem o homem dar nomes e sentidos? O objeto também olha o homem e não apenas o homem olha o objeto:

\begin{abstract}
A que se comunica o candeeiro? E a montanha? E a raposa? A resposta é a seguinte: ao homem. Não se trata de um antropomorfismo. A verdade desta resposta manifesta-se no conhecimento e talvez também na arte. Além disso: se o candeeiro, a montanha e a raposa não se transmitissem ao homem, como os denominaria ela? Mas denomina-os: ele comunica-se denominando-os (Benjamin, 2001, pp. 180-181) (itálico acrescido).
\end{abstract}

Se aceitamos que objetos falam aos homens, não poderíamos insistir na questão de que o sensível não seria o grito impulsionador da designação? $\mathrm{O}$ ato designativo não se expandiria apenas do cognitivo realizando-se em linguagem, mas da própria força metafórica que nos habita? E podemos considerar a força comunicável dos objetos, na medida em que são eles que provocam a força criadora do homem designativo. Os objetos estão ali, à nossa frente, construídos ou não pelo homem, e que, de alguma forma, geram impulsos: "as diferenças entre as linguagens (...) se diferenciam segundo a sua densidade, ou seja, gradualmente: e isso tanto no sentido da densidade do comunicante (...), como no do comunicável (...) na comunicação (Benjamin, 2001, p. 183). O objeto seria o comunicável e o homem o comunicante, que pela interação constituem o processo da comunicabilidade. Se comunicabilidade é interação, ambos os elementos que a constituem - objeto e homem - são vetores da práxis comunicativa.

E pela duplicidade do movimento relacional, a agência do sujeito sobre os objetos e dos objetos sobre o sujeito, que o pneuma se instaura.

\section{Da metáfora - o pneuma da linguagem}

Pleiteamos que a metáfora seria o pneuma da linguagem, o grito que ainda não foi articulado, e como diria Derrida (1999, p. 302) "um sopro falante, cantante, sopro de 
linguagem, mas sopro inarticulado". Como poderíamos sentir esse sopro em nosso corpo, agora, ouvindo esse texto ou o lendo? Seria no próprio movimento do ar em nosso corpo: inspiramos - o sopro sem articular, mas já cantante -, e na expiração, sua articulação. Daí entender o que seja o nosso pneuma corporal, que se constitui por dois movimentos, inspiração e expiração. É por esse/nesse pneuma corporal que o sensível se manifesta, seja ele acionado pelos cinco sentidos, seja pelas nossas emoções captadas e produzidas, e assim por diante. Se, por exemplo, levo um susto, a minha inspiração é mais profunda, e o grito ecoa pelos meus membros e órgãos, se quero contra-argumentar algo que me incomoda o pneuma se acelera. Observem que antes de se expressar em linguagem, momentos sensíveis se processaram (susto, ansiedade, vontade,...), e inspiro para reagir em linguagem.

O sensível força o grito metafórico, que para se realizar precisa inspirar o ar inarticulado para alcançar a expiração articulada. Ele forja o grito, cuja pulsão metafórica encontra no corpo o vetor respiratório; o grito está no corpo, cuja dinâmica o injeta para o momento da designação. Mesmo que tentássemos aplicar a dicotomia tradicional sobre a natureza do sentido metafórico, ou seja, sentido literal recebendo um sentido figurado, não há como dar ao sentido literal o direito do primeiro estágio da linguagem se é pelo grito primeiro que ela surge. E se aceitamos o grito metafórico da linguagem, também não podemos creditar a esse grito apenas a tessitura cognitiva; o cognitivo pode emergir com o sensível, mas isoladamente não o constrói; “[o grito metafórico] trata-se de uma língua pura de toda suplementariedade" (Derrida, 1999, p. 300). Derrida $(1999$, p. 302) explica esse momento do sensível da língua pura, quando formula que

a criança saberá falar quando as formas de seu mal-estar puderem substituir-se umas pelas outras; poderá então deslizar de uma linguagem a outra, deslizar de um signo por debaixo do outro, jogar com as substâncias significantes: entrará na ordem do suplemento, aqui determinada como ordem humana: não chorará mais saberá dizer "sinto dor".

\section{Da "suplementariedade" ao cognitivo}

Quando o idealizador do projeto, o escritor e pesquisador Wills Leal, designou o local da cinematografia brasileira como "Roliúde Nordestina", não estaria ele primeiramente dando o grito metafórico de identidade? A força que o ser humano tem de 
territorializar sua identidade não seria um grito? Este grito não estaria tocando a pele do homem que sempre visa marcar seu território? Não é à toa que o ser social busca sua propriedade, sua casa, suas coisas, sua intimidade e os defende a qualquer preço. $\mathrm{O}$ grito primitivo está aí presente, mas já com as possibilidades de realização de "jogar com as substâncias significantes", que se exteriorizam junto ao cognitivo que o atravessa. Ou seja, é na organização da "suplementariedade" que o processo cognitivo se instala e se apresenta: "como o conhecimento é representado (...), como linguagem é entendida, como imagens são compreendidas e com o que os processos mentais subscrevem inferências" (Richards et al. 1993, p. 60) (itálicos acrescidos). Enfim, posso entender a "suplementariedade" como o caminho de expansão e distribuição designativa do grito primitivo da linguagem pura, se não for sua única possibilidade de eclosão e emergência. Aceitando essa argumentação, podemos propor que, no momento de emergir, tal "suplementariedade" aciona o capital cognitivo, ou seja, 'informações' adquiridas por inferências histórico-culturais que se movem no processo da designação, situadas e de acordo com o tempo e espaço em que as metáforas se realizam. Ao aventar sobre o que estamos chamando de capital cognitivo, esclarecemos que não estamos preocupados com os padrões classificatórios nem com pressupostos teóricos de ciências cognitivas específicas, mas sim com uma proposta de aceitar o 'cognitivo' como um campo de constituição metafórica que se utiliza de conhecimentos de mundo que se armazenam na mente, de tal forma que nos possibilitam construir (sentir e perceber) na "suplementariedade" da linguagem a teia complexa e rica de sentidos 'sentidos'.

O sentido da metáfora "Roliúde Nordestina" pode ser explicado pelo armazenamento de três campos cognitivos que se interrelacionam: a possível (se assim o acreditarmos) hibridação cultural entre estudinenses e brasileiros; a relação simbólica das territorializações Hollywood e Nordeste; e historicidades de glamour e aridez de cada território, respectivamente. Ao buscarmos uma análise dos elementos cognitivos que contribuem para o sentido da referida metáfora, não os estamos enclausurando, porquanto efeitos de sentidos não se fecham em valorações finitas, haja vista os estudos que postulam ser a "interpretação" uma estrada infinita (Rajagopalan, prelo).

Como mencionado, o primeiro plano cognitivo que se instala em "Roliúde Nordestina" é o conhecimento de duas culturas - brasileira nordestina e estudinense hollywoodiana - com performativos sócio-econômicos tão díspares que nos leva à ideia de que "Roliúde Nordestina" excede ao que Hall (2000) chamaria de "comunidade 
imaginada". O sentido de "comunidade imaginada" se estabelece por histórias que vão compor uma comunidade, um agrupamento, um 'lugar': no caso, a metáfora inventa uma tradição, que, segundo Hobsbawn e Ranger (citado em Hall 2000, p. 54), seria um "conjunto de práticas, de natureza real ou simbólica, que buscam inculcar certos valores e normas de comportamentos (...)". Se "comunidade imaginada" é lugar simbólico, imagine os graus de simbologias que se entrecruzam nos lugares Nordeste e Hollywood. Não é à toa que tal designação se tornou notícia de jornal! Se uma comunidade 'real' já é construção imaginada de uma identidade cultural, imagine uma designação - prá lá de imaginada - com proposta de hibridação cultural cujos valores e crenças aos olhos do imaginário coletivo são conflituosas.

Junto a essa invenção identitária de um nordeste hollywoodiano, Bhabha (1998, pp. 238-239) nos lembra que as contingências históricas seriam os fundamentos da necessidade de elaborar estratégias legitimizadoras de "minorias dentro das divisões geopolíticas", minorias aqui entendidas como comunidades em busca de seu perfilamento identitário. Não estaria aí a tentativa do set em Cabaceiras, uma minoria cinematográfica, em legitimar sua identidade buscando o famoso glamour do tapete vermelho que habita a indústria do cinema americano? Pela nominalização "Roliúde", que se junta ao determinante territorial Nordestina, pode-se dizer que a expressão metafórica "Roliúde Nordestina" é uma estratégia de linguagem para que determinado lugar alcance sua legitimação, e que talvez, sem tal recurso, não o conseguisse. Como o próprio fundador do set em Cabaceiras diz: “Apesar das analogias, (...) a palavra 'roliúde’ é apenas marketing que faz questão de grafar "márquete"”.

O campo cognitivo acionado pelo conhecimento de culturas mostra não só uma "Roliúde Nordestina" que extrapola o sentido de uma "comunidade imaginada", que visa “inculcar certos valores" não necessariamente absorvidos pelos agentes culturais, mas também um recurso de "legitimar" a importância identitária do set Cabaceiras, já que é uma "minoria no espaço geopolítico" da cinematografia. O que parece ter ocorrido nesse processo de designação metafórica foi a rearticulação de sentidos que inscreveu não só uma identidade cultural mais glamourosa para chamar atenção, como também a autolegitimação pelo uso de homofonias transliteradas - de Hollywood a "Roliúde"9 . No entanto, a questão da rearticulação sígnica é mais complexa, não se restringindo apenas à

\footnotetext{
${ }^{9}$ No senso comum faz-se a relação do " $h "$ da língua inglesa ao "r" (forte) da língua portuguesa.
} 
adaptação fonética e ao recurso de marketing. Segundo Bhabha (1998, p.240), cultura "é a marca do espaço conflituoso mas produtivo, no qual a arbitrariedade do signo de significação cultural emerge no interior das fronteiras reguladoras do discurso social". "Roliúde Nordestino" constrói, sem dúvida, um espaço "produtivo" de sentidos culturais pela travessia transnacional, mas também é "conflituoso", porquanto os discursos sociais de cada espaço nacional divergem:

Torna-se crucial distinguir entre a semelhança e a similitude dos símbolos através de experiências culturais diversas - a literatura, a arte, o ritual musical, a vida, a morte - e da especificidade social de cada uma dessas produções de sentido em sua circulação como signos dentro de locais contextuais e sistemas de valor específicos. (...) O discurso natural(izado), unificador, da "nação", dos "povos" ou da tradução "popular" autêntica, esses mitos incrustados da particularidade da cultura, não pode ter referências imediatas. A grande, embora desestabilizadora, vantagem dessa posição é que ela nos torna progressivamente conscientes da construção da cultura e da invenção da tradição (Bhabha, 1998, p. 241).

O conhecimento cultural que se instala em "Roliúde Nordestina" pode se ampliar para outras duas inferências: uma da ordem da territorialização e outra da historicidade. $\mathrm{Na}$ primeira, territorialização, Haesbaert (2006, p. 40) nos oferece um tratamento de território pela vertente "simbólico-cultural: [que] prioriza a dimensão simbólica em que o território é visto, sobretudo, como o produto da apropriação/valorização simbólica de um grupo em relação ao seu espaço vivido". A dimensão simbólica de Hollywood e do Nordeste habita espaços sociais organizados pela historicidade e geograficidade específicas. Mas, segundo seu fundador é possível coordenar a relação entre os territórios pela prática cinematográfica: "o Estado americano tem muitas semelhanças com o município paraibano: Califórnia e Cabaceiras têm cenários desérticos, luminosidade, variedade de sets e mão de obra barata". Apesar da justificativa de Leal de que as territorializações de Hollywood e Cabaceiras se permeiam por equivalência, não se pode esquecer a fala de Ana Bárbara Ramos, na mesma reportagem: "Hollywood não é só um cenário. Há estúdios, dinheiro circulando. Cabaceiras não é isso, é um set de locação”. Nessa vertente simbólicocultural entra, então, o condicionamento econômico que perfila os territórios simbólicos: "na dimensão espacial das relações econômicas, o território [é visto] como fonte de recursos e/ou incorporado no embate entre classes sociais e na relação capital-trabalho" (Haesbaert, 2006, p.40). E, nas relações econômicas, Hollywood e Cabaceiras destoam 
pelas fontes de recursos e de relações capital-trabalho, tendo em vista as imagens geográficas, a seguir, que pontuam a ruptura simbólica entre os territórios:

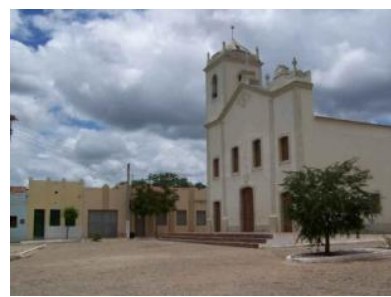

Figura II

Centro de Cabaceiras ${ }^{10}$

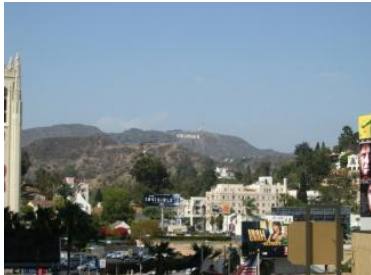

Figura III Cercanias de Los Angeles ${ }^{11}$

A segunda inferência é expansão da primeira, porquanto, ao se falar de historicidade, geograficidade e territorialização atinge-se à questão de pertença identitária (Vattimo, s/d), ou seja, as narrativas simbólicas constitutivas de uma Hollywood e de uma Cabaceiras devem criar um motivo para que o pertencimento se manifeste: o motivo está aí, a ação cinematográfica. Mas será que tal metáfora, em seu grito identitário, levanta o conhecimento de que "um processo objetivo no qual estamos inseridos (...) é um modo de estarmos conscientes dessa pertença" (Vattimo, s/d, p. 11)? A noção de pertença pode falhar nesse caso: há território, mas "consciência dessa pertença" fica duvidosa, já que riqueza e glamour não grudam no território nordestino.

Mas não importando a glorificação de pertença cultural, nessas idas e vindas das inferências cognitivas, a designação metafórica do set cinematográfico brasileiro, "Roliúde Nordestina", tornou-se notícia midiática, chamou a atenção, criou estranhamento, atingindo ao seu objetivo de se fazer ouvir. E é no próprio estranhamento cognitivo entre culturas, territórios e histórias que o sentido metafórico se faz reconhecido.

\section{A balança metafórica entre o grito e o cognitivo}

É importante reforçar que a designação metafórica não se constitui apenas do grito primitivo inarticulado. Como comentamos anteriormente, o sensível emerge também pela sua articulação, que passa a ser a "suplementariedade" desse primeiro grito, haja vista a comunicabilidade entre sujeitos e objetos e vice-versa. E é na articulação linguajeira que o

\footnotetext{
${ }^{10}$ Imagem retirada do site www.panoramio.com/photos, último acesso janeiro de 2009.

${ }^{11}$ Imagem retirada do site www.adrenaline.com.br/forum, último acesso janeiro de 2009.
} 
campo cognitivo se expressa. Por exemplo, a categorização Bollywood parece demonstrar mais "gastura" de uso em contrapartida à de "Roliúde Nordestina", porquanto esta pelo estranhamento cognitivo dá mais relevo ao grito primitivo de identidade. A gastura da "moeda" Bollywood, uma fusão morfológica de Bombaim (antigo nome de Mumbai/Índia, cidade onde se concentra esta indústria) com Hollywood, se deve ao contexto históricoecônomico na medida em que a designação não mais processa estranhamento cognitivosimbólico entre os territórios (Mumbai e Hollywood) para gritar sua identidade. A riquesa e glamour de Bollywood, nome conhecido internacionalmente da indústria cinematográfica indiana, são tão vastas quanto a de Hollywood, senão maior, tanto que no seu bojo engloba outras cinematografias, tais como Kollywood, Dollywood, Mollywood. Mesmo que híbrida morfologicamente, a nomeada cinematografia indiana não clama sua identidade por um grito de estranhamento, as estatísticas econômicas e difusoras revelam que tanto Bollywood quanto Hollywood têm sua própria identidade simbólica, independentes uma da outra. Em contrapartida, o set de Cariri se divulga midiaticamente pelo grito do estranhamento: une a simplicidade icônica - carroça, boi, terra batida, sertão árido - ao glamour de Hollywood - aparatos tecnológicos, disponibilidade a quaisquer recursos -, apesar da correspondência homofônica que cria - "Roliúde" $\{($ Holly $=[$ Roli $])+($ wood $=$ [úde])\}. Podemos confirmar as diferenças pelos referenciais territoriais de cada designação:

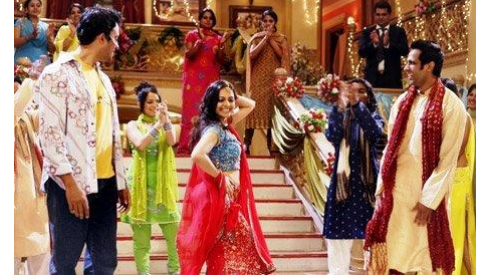

Figura IV Bollywood

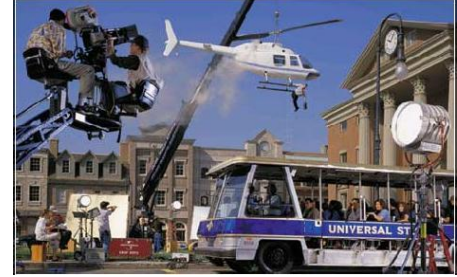

Figura V Hollywood

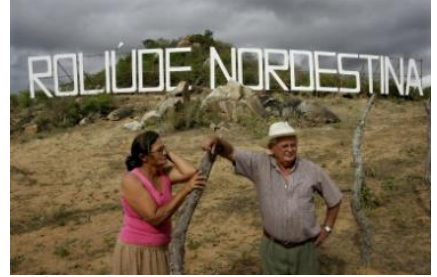

Figura VI

Roliúde

De um ponto de vista até ortodoxo, aventamos a possibilidade de os nomes Hollywood e Bollywood serem nomes próprios cujas origens de sentido históricoterritorial se perderam no processo de suas categorizações, e que 'Roliúde' grita uma homofonia linguística, que traduz uma unidade 'heterocultural' inconciliável. E, na medida em que a valoração de estranhamento atinge muito mais à designação 'Roliúde', posso dar a ela a natureza de um grito do sensível mais forte que clama por identidade, enquanto 
Hollywood e Bollywood expressariam processos designativos decorrentes de uma comunicabilidade já gasta pelo uso.

\section{Ponderação}

Pergunto o papel da mídia na designação metafórica de "Roliúde Nordestina". Essa imagem midiática, como diz Goody (citado em Pallares-Burke, 2000, p. 37) "não criou propriamente o evento [inauguração de um set cinematográfico brasileiro], mas provocou, sem dúvida, uma espécie de contágio" - um contágio cognitivo-simbólico de entrecruzamentos de territórios, culturas e histórias, que, mesmo dissonantes, ecoam em busca de uma legitimação identitária. Wills Leal, não importando as políticas de representação de sua metáfora, revalida o que seja sentido metafórico: o grito primitivo da linguagem pura que emerge em "suplementariedade", ou seja, um grito do corpo-sensível, que, para ser ouvido, tece estranhamentos cognitivos para manifestação articulada da linguagem.

\section{REFERÊNCIAS}

ARISTÓTELES. Physica VIII. Tradução Leonel Vallandro. Porto Alegre: Globo, 1969.

BAITELLO JUNIOR, Norberto. O olho do furacão: a cultura da imagem e a crise da invisibilidade. Disponível em: <www.dubitoergosum.xpg.com.br>. Acesso em: 1 abr 2010 .

BHABHA, Homi . O Local da Cultura. Tradução Míriam Ávila et al. Belo Horizonte: Editora UFMG, 1998.

BENJAMIM, Walter. Sobre a linguagem em geral e sobre a linguagem humana. Tradução Maria L. Moita, Maria A. Cruz, Manuel Alberto. In: BENJAMIM, W. Sobre Arte, Técnica, Linguagem e Política. Lisboa: Relógio d'Água, 1992.

BRANDÃO, Junito de S. Mitologia Grega. Vol. I. Rio de Janeiro: Vozes, 1991.

DERRIDA, Jacques. Gramatologia. Tradução Miriam Chnaiderman e Renato Janine Ribeiro. São Paulo: Editora Perspectiva, 1999.

As Margens da Filosofia. Tradução Joaquim Torres Costa e António M.

Magalhães São Paulo: Papirus, 1991. 
HAESBAERT, Rogério. O Mito da Desterritorialização. Do "fim dos territórios" a multiterritorialidade. São Paulo: Bertrand Brasil, 2006.

HALL, Stuart. A Identidade Cultural na Pós-Modernidade. Tradução Tomaz Tadeu da Silva e Guacira Lopes Louro. Rio de Janeiro: DP\&A, 2000.

MACHADO, José Pedro. Dicionário Etimológico da Língua Portuguesa. Lisboa: Livros Horizontes, 1995.

MARTINS FERREIRA, Dina. Identidade feminina no espaço político: percurso simbólico na ecologia da linguagem. In: MARTINS FERREIRA, D. e RAJAGOPALAN, K. (orgs.). Políticas em Linguagem: Perspectivas identitárias. São Paulo, Ed. Mackenzie. 2006, pp.277-298.

PALHARES-BURKE. Maria Lucia G. As Muitas Faces da História. Noves entrevistas. São Paulo: Ed. UNESP, 2000.

PLATÃO. Crátilo. Tradução Dias Palmeiras. Lisboa: Livraria São Costa Ed., 1994.

RAJAGOPALAN, Kanavillil. Por uma Linguística Crítica - Linguagem, identidade e a questão ética. São Paulo: Parábola, 2003.

A 'dadidade' dos dados na pragmática. In: GONÇALVES, A. (org.). Ciências da Linguagem: O fazer científico? Vol. II. Campinas: Mercado das Letras, prelo.

RICHARDS, Jack C. , PLATT, John , PLATT, Heidi H. Dictionary of Language Teaching \& Applied Linguistics. United Kingdom: Longman, 1993.

VATTIMO, Gian. O Fim da Modernidade - Niilismo e hermenêutica na cultura pósmoderna. Tradução Maria de Fátima Boavida. Rio de Janeiro: Presença, s/d. 